Article

\title{
Pt-Ni Seed-Core-Frame Hierarchical Nanostructures and Their Conversion to Nanoframes for Enhanced Methanol Electro-Oxidation
}

\author{
Shutang Chen ${ }^{1}$, Haibin $\mathrm{Wu}^{1}{ }^{1}$, Jing Tao ${ }^{2}$, Huolin Xin ${ }^{3}$, Yimei Zhu ${ }^{2}$ and Jingyi Chen ${ }^{1, * \mathbb{C}}$ \\ 1 Department of Chemistry and Biochemistry, University of Arkansas, Fayetteville, AR 72701, USA; \\ chenstwxh@gmail.com (S.C.); wuhb999@gmail.com (H.W.) \\ 2 Condensed Matter Physics and Materials Science Department, Brookhaven National Laboratory, Upton, \\ NY 11973, USA; jtao@bnl.gov (J.T.); zhu@bnl.gov (Y.Z.) \\ 3 Center for Functional Nanomaterials, Brookhaven National Laboratory, Upton, NY 11973, USA; \\ xinhuolin@gmail.com \\ * Correspondence: chenj@uark.edu; Tel.: +1-479-575-6203
}

Received: 1 December 2018; Accepted: 26 December 2018; Published: 3 January 2019

\begin{abstract}
Pt-Ni nanostructures are a class of important electrocatalysts for polymer electrolyte membrane fuel cells. This work reports a systematic study on the reaction mechanism of the formation of Pt-Ni seed-core-frame nanostructures via the seeded co-reduction method involving the Pt seeds and selective co-reduced deposition of $\mathrm{Pt}$ and $\mathrm{Ni}$. The resultant structure consists of a branched $\mathrm{Pt}$ ultrafine seed coated with a pure $\mathrm{Ni}$ as rhombic dodecahedral core and selective deposition of $\mathrm{Pt}$ on the edges of the cores. Both the type of Pt precursor and the precursor ratio of $\mathrm{Pt} / \mathrm{Ni}$ are critical factors to form the resulting shape of the seeds and eventually the morphology of the nanostructures. These complex hierarchical structures can be further graved into hollow Pt-Ni alloy nanoframes using acetic acid etching method. The larger surface area and higher number of low coordinate sites of the nanoframes facilitate the electrocatalytic activity and stability of $\mathrm{Pt}-\mathrm{Ni}$ alloy for methanol oxidation as compared to their solid counterparts. This study elucidates the structural and compositional evolution of the complex nanoarchitectures and their effects on the electrocatalytic properties of the nanostructures.
\end{abstract}

Keywords: bimetallic nanoparticles; platinum; nickel; electrocatalysis

\section{Introduction}

Platinum (Pt)-containing nanoparticles have attracted tremendous attentions in recent years because of their intriguing properties and broad potential applications in polymer electrolyte membrane fuel cells (PEMFCs) [1,2]. To improve electrocatalytic activity with cost effectiveness, $3 d$-transition metals are incorporated into the pure Pt lattice to form Pt-based bimetallic catalysts for PEMFC. For example, $\mathrm{Pt}_{3} \mathrm{Ni}$ (111) surface was demonstrated to be 10- and 90-fold more active than the $\mathrm{Pt}(111)$ surface and the commercial $\mathrm{Pt} / \mathrm{C}$ catalysts, respectively, for the cathodic oxygen reduction reaction (ORR) of PEMFCs [3]. Since then, many efforts have been made to synthesize Pt-Ni nanoparticles with various sizes, shapes, and compositions for improvement of ORR catalytic activity. The $\mathrm{Pt}_{3} \mathrm{Ni}$ octahedral nanoparticles showed $\sim 4$ times better than the commercial $\mathrm{Pt} / \mathrm{C}$ catalysts $[4,5]$ while the ORR activity of $\mathrm{Pt}_{3} \mathrm{Ni}$ octahedra was found $\sim$-fold higher than that of the nanocubes with similar size [6]. A nominal composition of PtNi nanoparticles displayed a 3-fold more active than $\mathrm{Pt}_{3} \mathrm{Ni}$ nanoparticles and 15 times better than $\mathrm{Pt} / \mathrm{C}$ [7]. Similar findings were reported that the activity varied with composition with PtNi octahedra 10-fold better than Pt/C [8]. Further extended study from the thin-film to the nanoscale showed that PtNi/multilayer Pt-skin nanoparticles had higher 
activity than PtNi/Pt-skeleton and PtNi nanoparticles [9,10]. More recently, an open-framework, $\mathrm{Pt}_{3} \mathrm{Ni}$ nanoframe, was demonstrated an enhancement factor of 36 in mass activity and 22 in specific activity, respectively for ORR compared to $\mathrm{Pt} / \mathrm{C}$ due to the large surface areas from both the interior and exterior of the frame structure [11,12]. The electrocatalytic activity of nanoframes could be further tuned by the anisotropic phase segregation of migration of $\mathrm{Pt}$ during synthesis and by controlling the architecture of the nanoframes [13-15]. The shape of the nanoframes could be tuned by the use of different surface ligands to yield tetrahedral and rhombic dodecahedral nanoframes, respectively [16]. On the other hand, studies reported that Pt rich $\{111\}$ surface on Ni-rich subsurface showed better electrocatalytic activity for ORR compared to Pt-rich corners/edges and slightly concave Ni-rich $\{111\}$ facets [17]. The electrocatalytic activity of the Pt-Ni nanostructures could be tuned by a thermal annealing process due to the structural reconstruction [18]. In addition to skin/skeleton surfaces and nanoframes, other morphologies with highly open nanoarchitectures such as porous structures [19-21], ultrathin nanowires [22-24], and atomic surfaces [25-29] could also facilitate adequate exposure of the active surfaces and the feasible mass transport for ORR [30,31].

Apart from the enhancement of ORR reaction, $\mathrm{Pt}-\mathrm{Ni}$ nanoparticles have been demonstrated to improve the cathodic methanol oxidation reaction (MOR) of PEMFC [32]. The modification of $\mathrm{Pt}$ electronic structure by $\mathrm{Ni}$ was attributed to the charge transfer from $\mathrm{Ni}$ to $\mathrm{Pt}$ atoms, thereby weakening CO poisoning of $\mathrm{Pt}$, and the $\mathrm{Pt}_{3} \mathrm{Ni}$ nanoparticles was found more active than $\mathrm{Pt}_{2} \mathrm{Ni}$ and $\mathrm{PtNi}$ for MOR [33]. The Pt-Ni octahedra with $\{111\}$ facets were more active then $\mathrm{Pt}-\mathrm{Ni} / \mathrm{C}$ and $\mathrm{Pt} / \mathrm{C}$ [34]. The open frame structures were more active catalysts than the solid nanoparticles for alcohol oxidations $[16,35,36]$. We demonstrated that other nanostructures with highly accessible surfaces including Pt-Cu nanodendrites [37], nanowires [38], core-frame and frame structures could enhance MOR activity [39]. In this work, we reported a seeded co-reduction method to synthesize the rhombic dodecahedral, hierarchical structure. Different from the previously-reported one-pot synthesis $[11-13,15,16]$, the heterogeneous nucleation of $\mathrm{Ni}$ on $\mathrm{Pt}$ seeds dominated, followed by selectively deposition of $\mathrm{Pt}$ on the edges and corners of the resulting seed-core rhombic dodecahedra to yield the seed-core-frame structures. The reaction mechanism was further investigated in detail in order to elucidate the important parameters for controlling the morphology of the complex structure. These nanoarchitectures could be further graved into hollow structures using the acetic acid etching method. The composition and degree of hollowing out could be controlled through both reaction temperature and time. Lastly, the electrocatalytic properties of these nanostructures were evaluated for MOR. The morphology-composition-activity-stability relationship was established and in all cases this unique set of nanostructures have better performance than the commercially-available $\mathrm{Pt} / \mathrm{C}$ catalysts.

\section{Results and Discussion}

\subsection{Synthesis of the Seed-Core-Frame Nanostructures}

The seed-core-frame nanostructures were synthesized by modifying our previously-developed seeded co-reduction method for bimetallic nanorods [40]. In this synthesis, aliphatic amines were used as both reductant and solvent, and a sequential injection method was applied to control the growth of the desired nanostructures. A two-step procedure was involved by first forming the $\mathrm{Pt}$ seeds prior to the injection of $\mathrm{Ni}$ precursors to yield the $\mathrm{Pt}-\mathrm{Ni}$ nanostructures. Figure 1 displays the electron microscopy characterization of the complex core-frame nanostructures, consisting of a branched Pt seed, a Ni core surrounding the seed, and a Pt-rich frame. The overall structure adopts a rhombic dodecahedral shape with the edge length of $20 \mathrm{~nm}$ as shown in the transmission electron microscope (TEM) overview image of the sample (Figure 1A) and the tomography snapshots of a single particle (Figure 1B). The high-resolution TEM (HRTEM) image of a representative nanostructure indicates that the nanostructure is single crystalline and its surface is rich in high Miller index facets (Figure 1C). The composition of each part of the nanostructure is visualized in the energy dispersive X-ray spectroscopy (EDS) mapping of Pt and Ni that matches well with the Z-contrast in the high-angle 
annular dark-field scanning transmission electron microscopy (HAADF-STEM) image, confirming the elemental distribution of $\mathrm{Pt}$ and $\mathrm{Ni}$ in the nanostructure (Figure 1D).
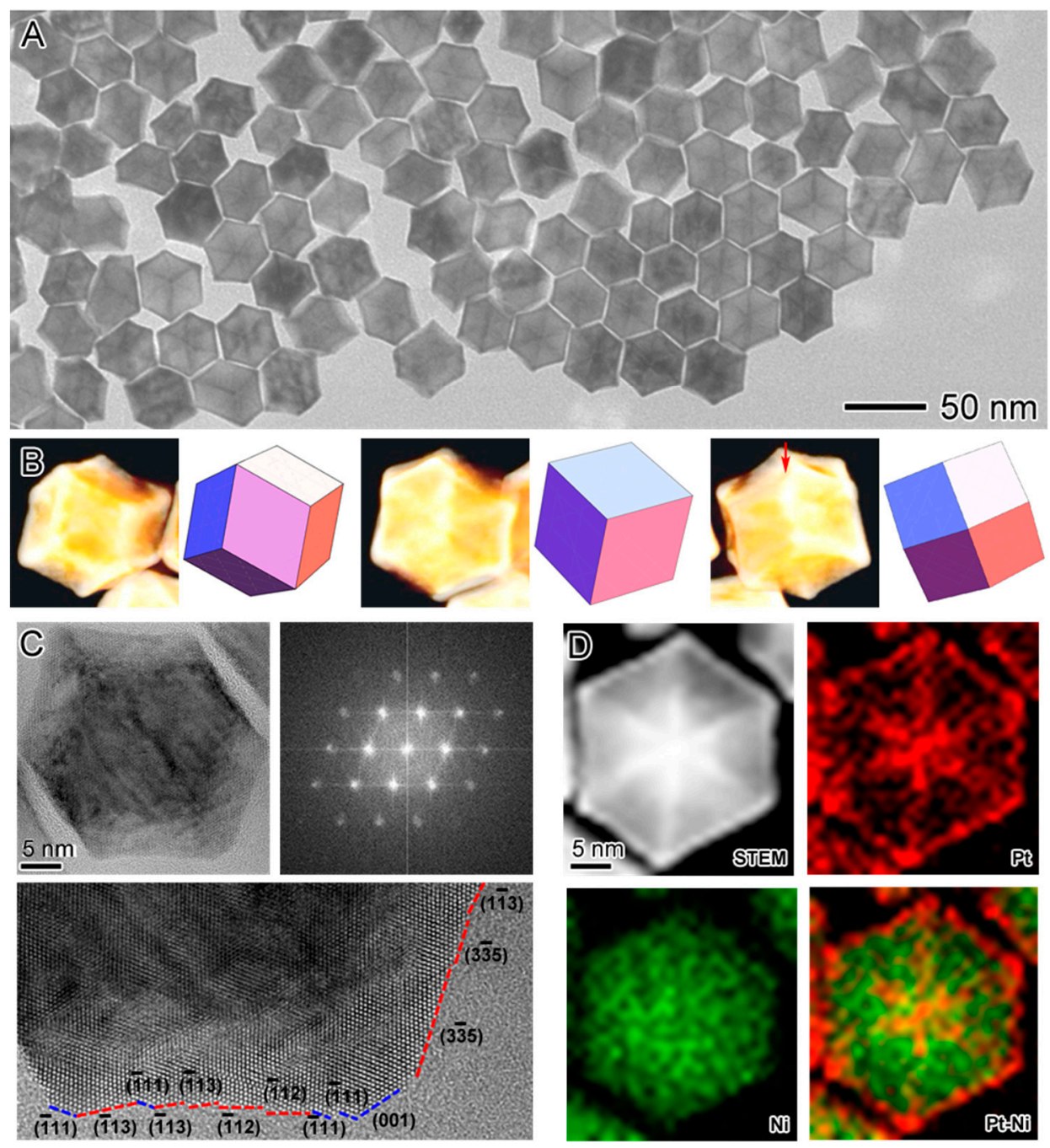

Figure 1. Transmission electron microscope (TEM) characterization of the seed-core-frame nanostructures. (A) TEM image overview of the polyhedral structure with an edge length of $\sim 20 \mathrm{~nm}$. (B) Tomography snapshots of a representative nanostructure with rhombic dodecahedral shape viewed from different zone axes [110], [111], and [100] from left to right. (C) High-resolution TEM (HRTEM) image of a representative nanostructure with its fast Fourier transformation showing a single crystalline pattern and its zoom-in view of the edges indexed with corresponding facets showing that its surface contains rich amount of high Miller index facets. (D) High-angle annular dark-field scanning transmission electron microscopy (HAADF-STEM) image and energy dispersive X-ray spectroscopy (EDS) mapping of a representative nanostructure that consists of $\mathrm{Pt}$ (red) and $\mathrm{Ni}$ (green) assembled as a seed-core-frame rhombic dodecahedron.

The anatomy of the seed-core-frame hierarchical structures was carried out by the removal of $\mathrm{Ni}$ from the aliquot samples taken from the synthesis. Figure 2A-D, displays the TEM images of the aliquot samples obtained from the synthesis after the sequential injection at different time periods. These images clearly shows that the rhombic dodecahedral nanoparticles forms immediately after the injection of Ni precursor and then gradually grows into larger nanoparticles. The size of these rhombic dodecahedra by measuring the diagonal of the nanoparticles gradually evolves from $10 \mathrm{~nm}$ to 20,30, and $40 \mathrm{~nm}$ within $20 \mathrm{~min}$ after the injection of Ni precursor. To confirm the seed-core-frame structure, these aliquot samples were further soaked in acetic acid that could remove pure Ni from 
the nanoparticles. Figure 2E-H, displays the TEM images of the corresponding etching products. Small branched Pt seeds $(<10 \mathrm{~nm})$ were found in the sample immediately after the injection of $\mathrm{Ni}$ precursors. Samples obtained at $2 \mathrm{~min}$ and $10 \mathrm{~min}$ after the Ni precursor injection contained larger branch-like structures as a result of the collapse of the frame nanostructures that were not well developed in the early stage of the synthesis. At $20 \mathrm{~min}$ later, the well-constructed nanoframes were observed in the sample. These results elucidate the morphology evolution during the formation of the seed-core-frame hierarchical structure.
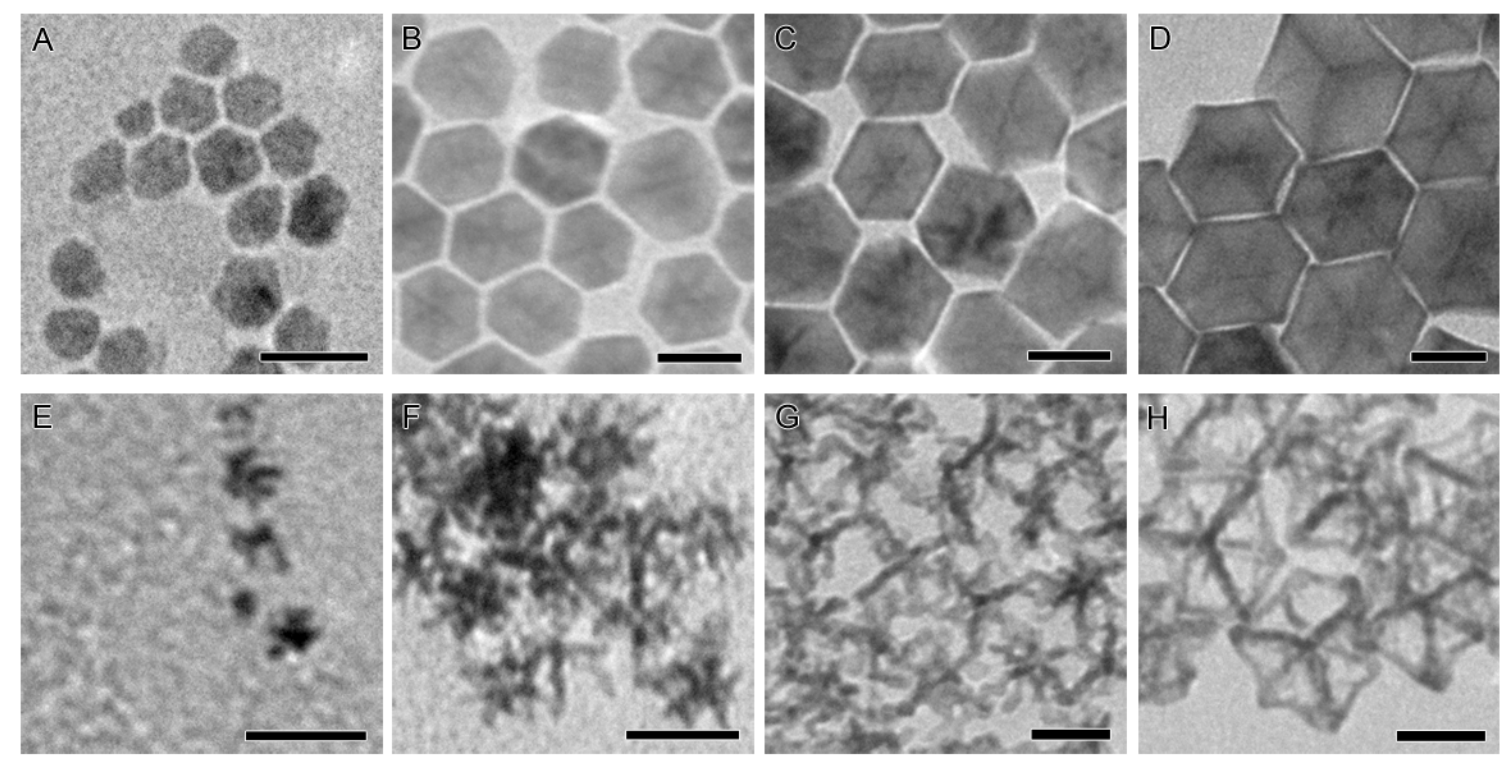

Figure 2. TEM images of the aliquot samples taken from the seeded co-reduction synthesis at different time points after the injection of Ni precursor. (A-D) Aliquot samples taken from the synthesis at $30 \mathrm{~s}$ (A), $2 \mathrm{~min}$ (B), $10 \mathrm{~min}$ (C), and $20 \mathrm{~min}$ (D). (E-H) Corresponding etching samples of (A-D) after incubation with acetic acid at $60{ }^{\circ} \mathrm{C}$ for $15 \mathrm{~h}$. The scale bars are $20 \mathrm{~nm}$.

The key to form the seed-core-frame hierarchical structure was further investigated by systematically altering the reaction conditions. The use of different aliphatic amines (C8-C18) and oleylamine has little effect on the resultant structures which all retain the rhombic dodecahedral shape (Figure 3A-D). However, the choice of Pt precursors is one of the key factors to obtain the branched $\mathrm{Pt}$ seeds as the foundation to form the rhombic dodecahedra and thus the core-frame structure. Figure $3 \mathrm{E}-\mathrm{H}$, displays the TEM images of the products from the synthesis using $\mathrm{Pt}(\mathrm{acac})_{2}, \mathrm{~K}_{2} \mathrm{PtCl}_{4}$, $\mathrm{K}_{2} \mathrm{PtCl}_{4}$ with oleic acid containing equivalent moles of $\mathrm{H}$ as $\mathrm{K}$, and $\mathrm{H}_{2} \mathrm{PtCl}_{6}$. The results suggest that the shape of the seeds (in the inset of Figure $3 \mathrm{E}-\mathrm{H}$ ) dictates the final bimetallic structure and the stronger the acidic condition the more favorable to the hierarchical structure. Furthermore, the feeding ratio of $\mathrm{H}_{2} \mathrm{PtCl}_{6}: \mathrm{Ni}(\mathrm{acac})_{2}$ also plays a role in the formation of the hierarchical structure (Figure 3I-L). The pure $\mathrm{H}_{2} \mathrm{PtCl}_{6}$ and pure $\mathrm{Ni}(\mathrm{acac})_{2}$ yielded highly branched $\mathrm{Pt}$ sea urchin nanostructures and irregular Ni nanoparticles, respectively. The high ratio of $\mathrm{H}_{2} \mathrm{PtCl}_{6}: \mathrm{Ni}(\mathrm{acac})_{2}(\geq 1: 1)$ resulted in slightly branched nanostructures or concave tetrahedra/octahedra while the ratio of $\mathrm{H}_{2} \mathrm{PtCl}_{6}: \mathrm{Ni}(\mathrm{acac})_{2}$ ranging from $>1: 1$ to 1:6 generated the hierarchical rhombic dodecahedra. In the latter, the size of the rhombic dodecahedra decreased with increased ratio of $\mathrm{H}_{2} \mathrm{PtCl}_{6}: \mathrm{Ni}(\mathrm{acac})_{2}$. This size decrease could be attributed to the presence of $\mathrm{Pt}-\mathrm{Ni}$ co-reduction from homogeneous nucleation in addition to heterogeneous nucleation on the $\mathrm{Pt}$ seeds as the concentration of $\mathrm{Ni}(\mathrm{acac})_{2}$ increases. The homogeneous nucleation depletes the concentration of both precursors for heterogeneous growth, resulting in the reduction of the particle size similar to those reported in the literature from homogeneous nucleation [11-13,15,16]. 


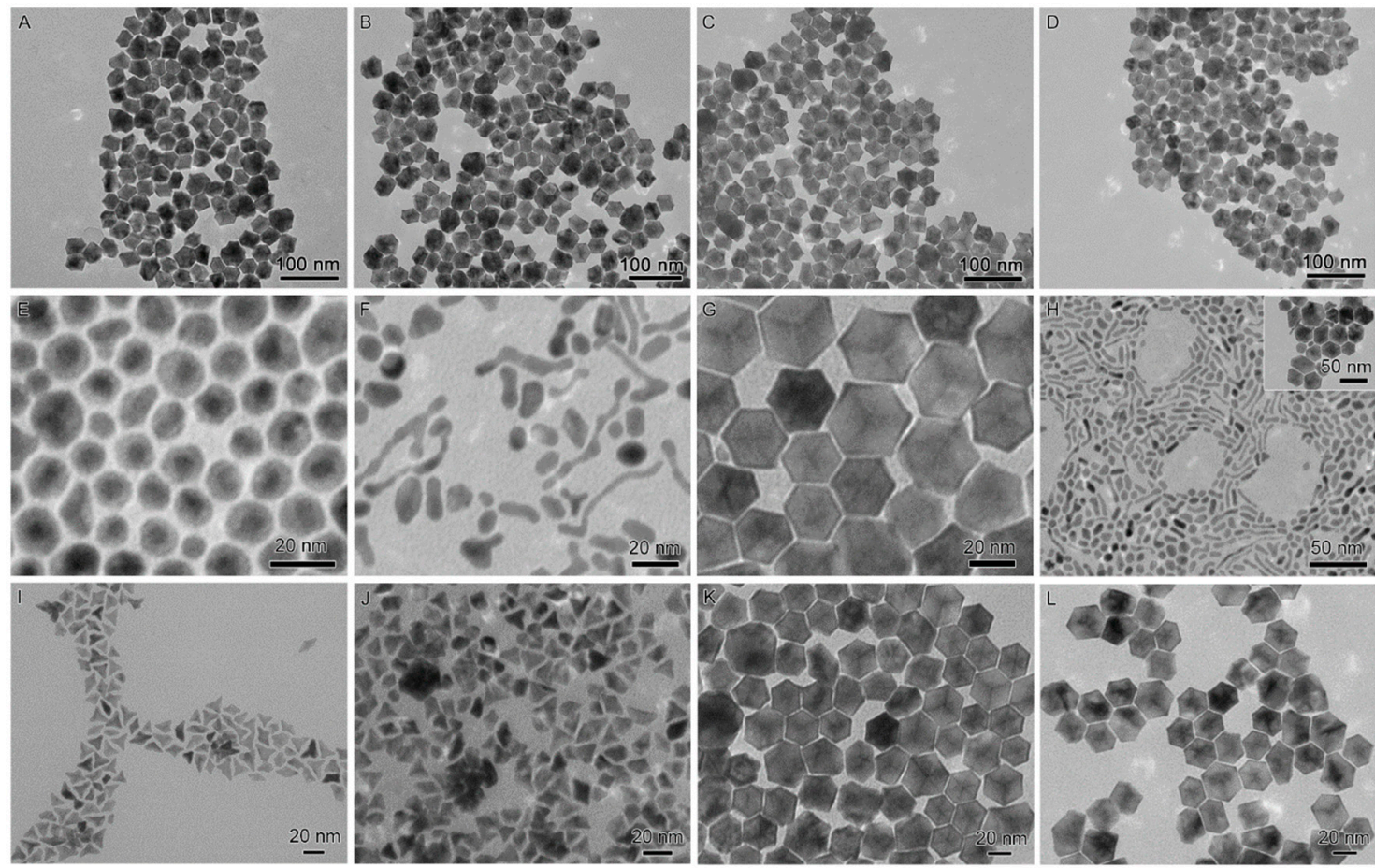

Figure 3. TEM images illustrating the morphology of the products from the syntheses by varying one reaction parameter at a time: (A-D) different solvents such as dodecylamine (DDA) (A), tetradecylamine (TDA) (B), hexadecylamine (HDA) (C), and octadecylamine (ODA) (D); (E-H) different precursors such as $\mathrm{Pt}(\mathrm{acac})_{2}(\mathbf{E}), \mathrm{K}_{2} \mathrm{PtCl}_{4}(\mathbf{F}), \mathrm{H}_{2} \mathrm{PtCl}_{6}(\mathbf{G})$, and $\mathrm{K}_{2} \mathrm{PtCl}_{4}+$ oleic acid $(\mathrm{H}) ;(\mathbf{I}-\mathbf{L})$ different molar ratio of $\mathrm{H}_{2} \mathrm{PtCl}_{6}: \mathrm{Ni}(\mathrm{acac})_{2}$ such as 10:1 (I), 1:1 (J), 1:4 (K), and 1:6 (L). Note that samples in (C), $(\mathbf{G}),(\mathbf{K})$ are three parallel reactions under the same condition using HDA as solvent and 1:4 molar precursor ratio of $\mathrm{H}_{2} \mathrm{PtCl}_{6}: \mathrm{Ni}(\mathrm{acac})_{2}$.

\subsection{Conversion of the Seed-Core-Frame Hierarchical Nanostructures to Nanoframes}

The seed-core-frame hierachical nanostructures could be converted to nanoframe structure through the etching method using $50 \% v / v$ acetic acid aqueous solution. After the etching process at $60{ }^{\circ} \mathrm{C}$ for $12 \mathrm{~h}$, the reaction yielded Pt-Ni nanoframes with an average edge length of $18.0 \pm 2.1 \mathrm{~nm}$ as shown in Figure 4A. The powder X-ray diffraction (XRD) pattern exhibited four peaks that could be indexed to the (111), (200), (220), and (311) diffractions of a face-centered-cubic (fcc) structure (Figure 4B). The peak positions were corresponding to 40.64, 47.08, 69.50, and 82.94 degrees located in between those of pure Pt and pure Ni metals. According to Vegard's law of the linear relationship between latter parameter and alloy composition [41], the XRD yielded a lattice constant of $a=3.83 \AA$, suggesting an approximate composition of $\mathrm{Pt}_{3} \mathrm{Ni}$ given that the lattice constants of pure $\mathrm{Pt}\left(a_{\mathrm{Pt}}\right)$ and pure $\mathrm{Ni}\left(a_{\mathrm{Ni}}\right)$ are $3.923 \AA$ and $3.523 \AA$, respectively. The elemental Pt and Ni appeared to uniformly distribute across the frame structure. The elemental analysis by atomic absorption (AA) gave a $\mathrm{Pt} / \mathrm{Ni}$ ratio of 73:27 in agreement with the estimated value from the Vegard's law. Using the Scherrer equation [42,43], the size of the crystalline domain was estimated to be $\sim 3.0 \mathrm{~nm}$ based on the full width at half-maximum (FWHM) of the (111) diffraction. The HRTEM image in Figure 4C indicates that $\mathrm{Pt}_{3} \mathrm{Ni}$ nanoframes were polycrystalline and the width of each edge was approximately $2-3 \mathrm{~nm}$ which was consistent with the measurement from the XRD band width. The HAADF-STEM image shows a frame architecture of 24 edges which retains its primary rhombic dodecahedral structure, while the EDS mapping confirms the composition of $\mathrm{Pt}$ and Ni alloy (Figure 4C). 

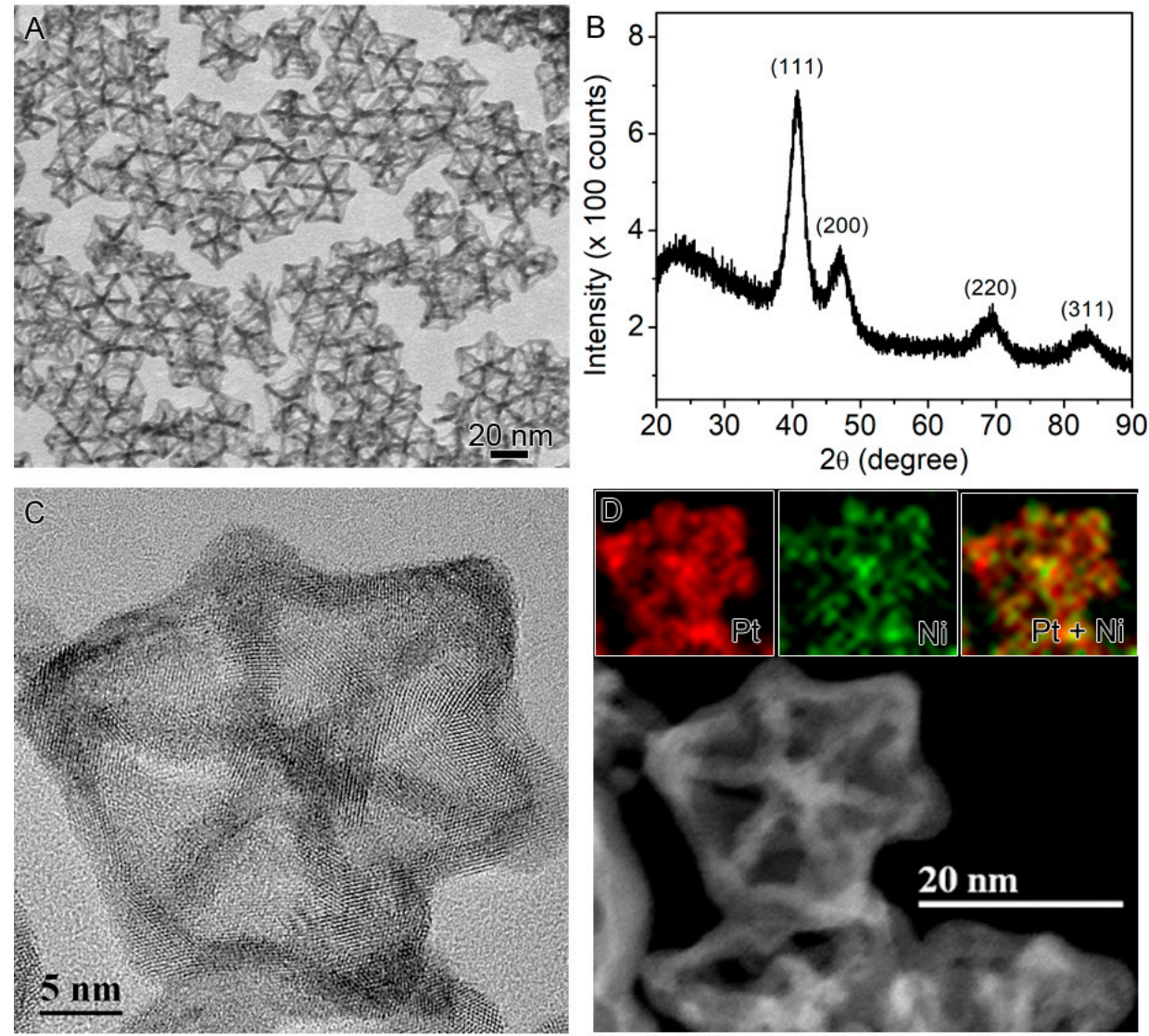

Figure 4. Characterization of Pt-Ni nanoframes: (A) TEM image showing the uniformity of the frame structure with an average edge length of $20 \mathrm{~nm}$; (B) X-ray diffraction (XRD) pattern of the nanoframes indicative of a fcc structure with the composition of $\mathrm{Pt}_{3} \mathrm{Ni}$ and grain size of $\sim 3 \mathrm{~nm}$; (C) HRTEM image of a representative nanoframe showing the polycrystalline nature of the structure and the edge thickness of 2-3 nm; and (D) HAADF-STEM image and EDS mapping of $\mathrm{Pt}$ (red) and $\mathrm{Ni}$ (green) indication the rhombic dodecahedral shape and the alloy distribution of $\mathrm{Pt}$ and $\mathrm{Ni}$.

The morphology and composition of etched products could be manipulated by controlling the temperature of the etching process. Based on the standard electrode potentials, the reactivity of $\mathrm{Ni}$ is more active than $\mathrm{H}$ and thus the etching reaction is as follows: $\mathrm{Ni}(s)+2 \mathrm{CH}_{3} \mathrm{COOH}(l) \rightarrow \mathrm{Ni}^{2+}(a q)$ $+2 \mathrm{CH}_{3} \mathrm{COO}^{-}(a q)+\mathrm{H}_{2}(g)$. Figure 5 displays the TEM images and the corresponding XRD patterns of the products from the reactions at two other temperatures $\left(0{ }^{\circ} \mathrm{C}\right.$ in ice bath and $20^{\circ} \mathrm{C}$ at room temperature) for $12 \mathrm{~h}$ in addition to the above condition at $60^{\circ} \mathrm{C}$. The results indicate the distinct difference in the morphology and composition of the products obtained at different temperatures. Both the rates of the etching process and diffusion are expected to increase as the temperature increases. At $0{ }^{\circ} \mathrm{C}$, the seed-core-frame nanostructures were partially emptied, resulting in the concave polyhedral nanostructures. When the temperature increases to $20^{\circ} \mathrm{C}$, the etching process yielded the nanoframes with ultrathin skeleton having very poor mechanical strength that are easy to collapse. The XRD patterns suggest that pure $\mathrm{Ni}$ still remains in these nanostructures with the product from the reaction at $0{ }^{\circ} \mathrm{C}$ having more pure $\mathrm{Ni}$ than that from the reaction at $20^{\circ} \mathrm{C}$. 

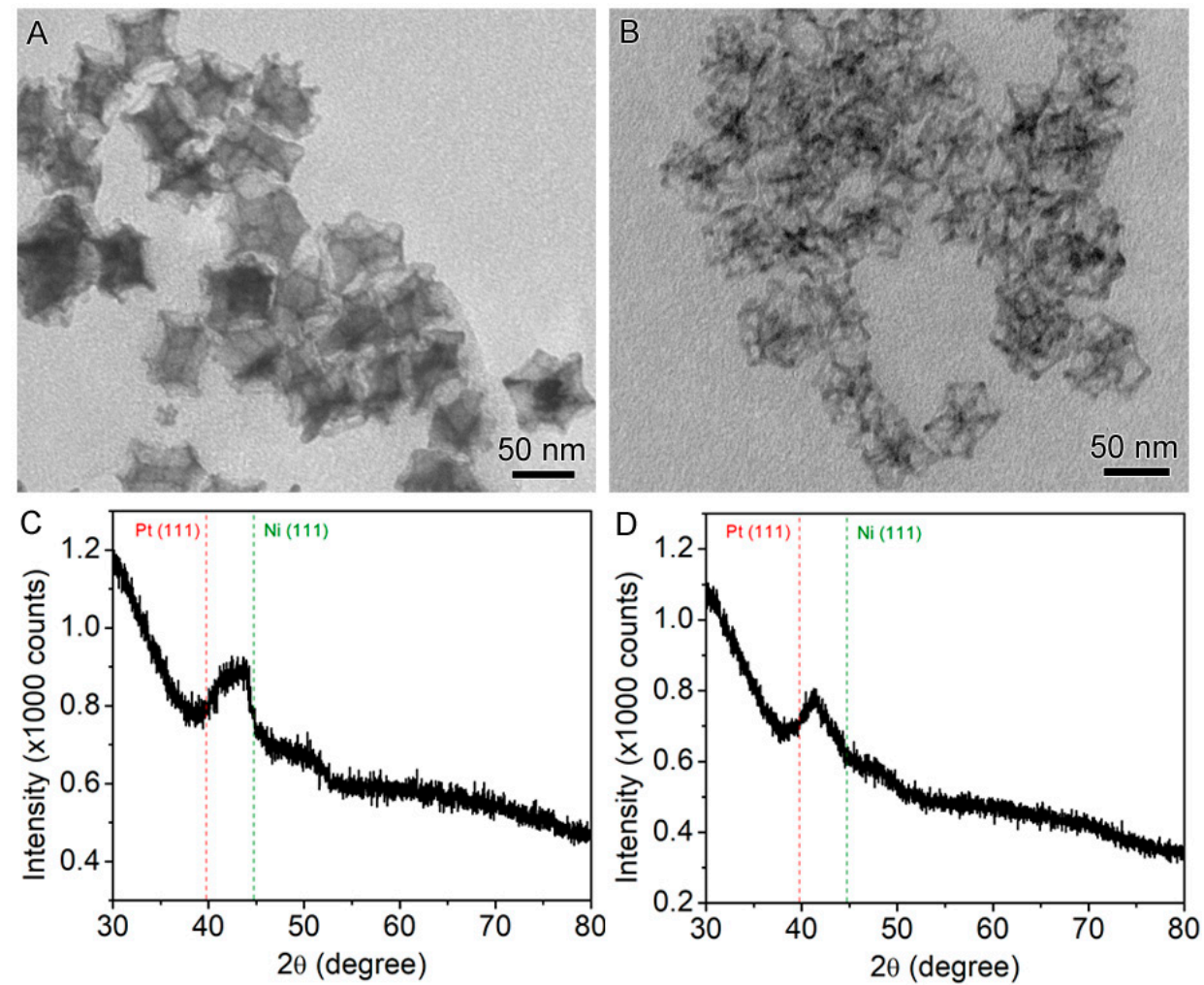

Figure 5. (A,B) TEM images of the samples via acetic acid etching at different temperatures: (A) $0{ }^{\circ} \mathrm{C}$ in ice batch and (B) $20^{\circ} \mathrm{C}$ room temperature. (C,D) Corresponding XRD patterns of the samples (A) and (B), respectively.

In addition to temperature, the reaction time could also affect the morphology and composition of the resultant products. The time-course study was carried out for the etching process at at $60{ }^{\circ} \mathrm{C}$ and the intermediate samples were collected and characterized by TEM and XRD. Figure 6 shows the XRD patterns of each intermediate sample indicating the compositional change during the course of etching reaction from initial Ni-rich composition to $\mathrm{Pt}-\mathrm{Ni}$ alloys. The insets display the TEM images of selective samples detailing the corresponding morphological evolution from the polyhedral solid nanoparticles to nanoframes. From these results, the etching process appeared to start from the planar surface of the polyhedral nanoparticles whose (110) faces were rich in $\mathrm{Ni}$, yielding concave polyhedra. A similar trend was observed during ORR under acidic conditions which the octahedral $\mathrm{Pt}-\mathrm{Ni}$ nanoparticles became concave octahedra with the edge and corner intact [44]. As the reaction proceeded, more $\mathrm{Ni}$ atoms were oxidized to $\mathrm{Ni}^{2+}$ ion and leached out from the concave structure, resulting in the frame of the rhombic dodecahedral structure. The composition of the skeletons was changed from almost pure $\mathrm{Pt}$ for the polyhedral solid nanoparticles to a mixture of a $\mathrm{Pt}-\mathrm{Ni}$ alloys and $\mathrm{Pt}_{3} \mathrm{Ni}$ for the nanoframes. It is implied that the diffusion rate of $\mathrm{Ni}$ to $\mathrm{Pt}$ was faster than that of $\mathrm{Pt}$ to $\mathrm{Ni}$ due to the Kirkendall effect $[45,46]$. Little compositional and morphological changes of the nanoframes were found after the sample were etched for $30 \mathrm{~h}$, suggesting that the $\mathrm{Pt}_{3} \mathrm{Ni}$ nanoframes were relatively stable under the acidic condition.

The electronic properties of $\mathrm{Pt}$ and surface properties for the $\mathrm{Pt}_{3} \mathrm{Ni}$ nanoframes were further examined by X-ray photoelectron spectroscopy (XPS) and Fourier transform infrared (FTIR) spectroscopy (Figure S1). The XPS peaks attributed to $\mathrm{Pt}_{4 \mathrm{f}}{ }^{5 / 2}, \mathrm{Pt}_{4 \mathrm{f}}{ }^{7 / 2}$ were well resolved. Both peaks were downshifted by 0.37 and $0.38 \mathrm{eV}$ for $\mathrm{Pt}_{4 \mathrm{f}}{ }^{5 / 2}$ and $\mathrm{Pt}_{4 \mathrm{f}}{ }^{7 / 2}$, respectively, as the structures evolved from polyhedra to concave polyhedra and nanoframes. It is suggested that partial charge was transferred from $\mathrm{Ni}$ atoms to Pt atoms as the Pt alloyed with Ni. This observation is consistent with the previous report [33]. After etching, the OLA and HDA ligands on the nanoparticles was replaced by acetic 
acid molecules. The FTIR characterization of the samples before and after etching with acetic acid. The spectrum of the polyhedra prior to the etching indicates the presence of OLA and/or HDA based on the assignments of characteristic peaks as follows: the oleyl and/or hexadecyl groups in the 2850-3000 $\mathrm{cm}^{-1}$ region, $v(\mathrm{C}=\mathrm{C})$ stretch mode at $1647 \mathrm{~cm}^{-1}$, and $\mathrm{NH}_{2}$ scissoring mode at $\sim 1590 \mathrm{~cm}^{-1}$. After etching, the spectrum of nanoframes capped by acetic acid shows the characteristic peaks of $-\mathrm{COO}^{-}$at 1562 and $1423 \mathrm{~cm}^{-1}$, but no peaks of oleyl and hexadecyl groups, suggesting that neither OLA nor HDA is present.
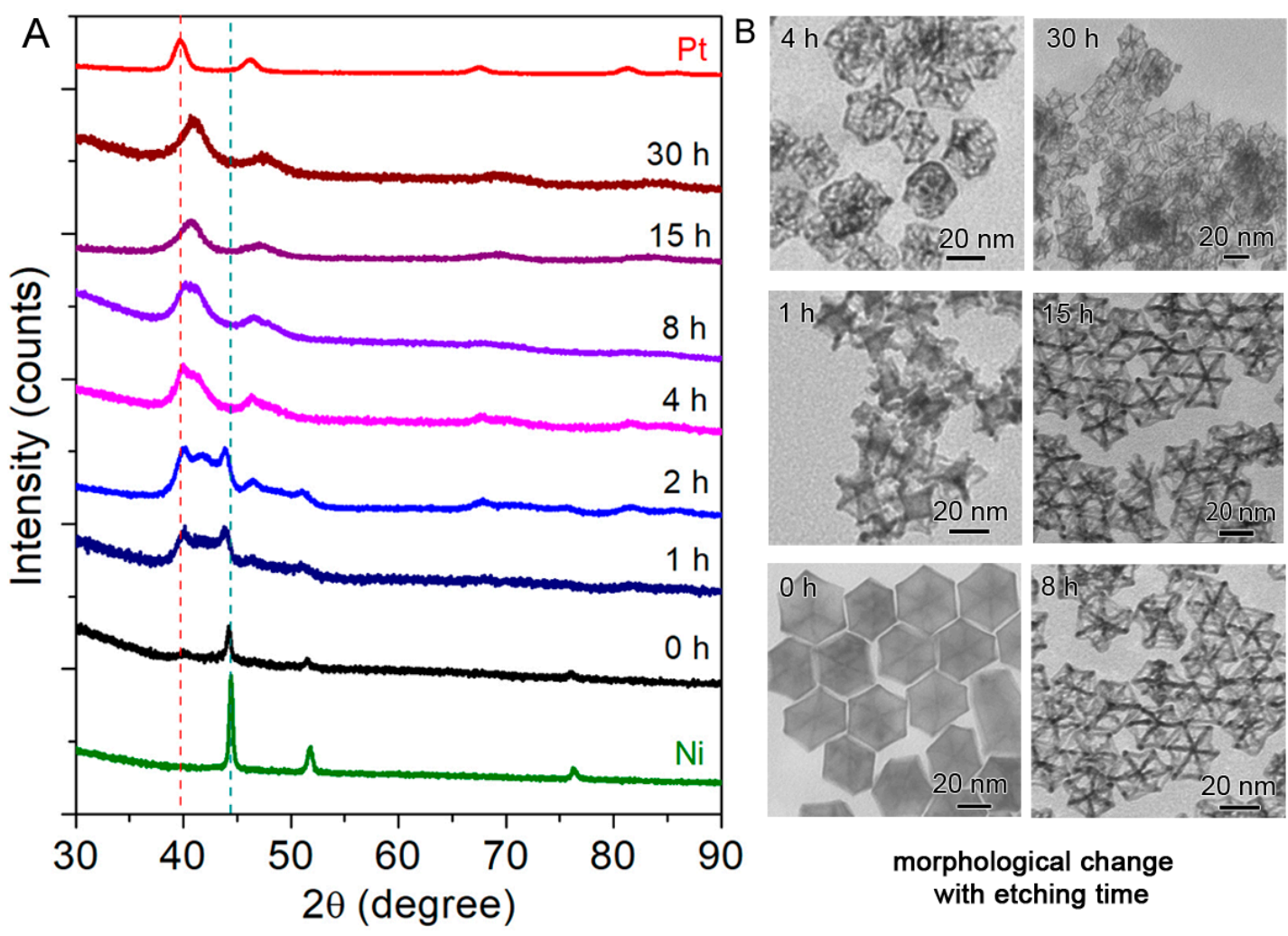
morphological change with etching time

Figure 6. Characterization of the aliquot samples taken from the etching process at different time points: (A) XRD patterns and (B) TEM images.

\subsection{Electrocatalytic Performance of the Pt-Ni Nanostructures for Methanol Oxidation Reaction (MOR)}

The electrocatalytic properties of the $\mathrm{Pt}-\mathrm{Ni}$ nanostructures were studied for MOR. The electrochemical active surface area (ECSA) of these nanocatalysts were characterized by cyclic voltammetry $(\mathrm{CV})$ using a $0.1 \mathrm{M} \mathrm{HClO}_{4}$ solution with a scan rate of $50 \mathrm{mV} / \mathrm{s}$ in a 3-electrode cell. The ECSA can be calculated by integrating the charge passing the electrode during the hydrogen adsorption/desorption with the potential ranging from $0.05 \mathrm{~V}$ to $0.4 \mathrm{~V}$ vs. reversible hydrogen electrode (RHE) after the correction of the double layer capacitive contribution [47]. The electrocatalytic activity of the nanocatalysts for MOR was examined in a $1 \mathrm{M} \mathrm{CH}_{3} \mathrm{OH} / 0.1 \mathrm{M} \mathrm{HClO}_{4}$ solution at a scan rate of $50 \mathrm{mV} / \mathrm{s}$. The electrocatalytic stability was evaluated by the chronoamperometry (CA) measurements performed at the peak current for $1200 \mathrm{~s}$ and by the ECSA changes after cycling. Figure 7 displays the structural characterization and the electrocatalytic properties of the butylamine-treated $\mathrm{Pt}-\mathrm{Ni}$ seed-core-frame nanostructures. The butylamine treatment is to ensure the good dispersity of the catalysts in aqueous solution for drop-cast ink preparation by replacing the surface ligand aliphatic amine with butylamine. After the ligand exchange process, little changes in neither composition nor morphology were observed. However, as mentioned above, the Pt-Ni seed-core-frame nanostructures are unstable in acidic solution due to the leach of pure $\mathrm{Ni}$ and structural reconstruction to form alloy nanoframes. The ECSA increases with time in the acid solution while the MOR activity decreases as 
indicated by the decrease in peak current density and the $\mathrm{CO}$ tolerance ability (i.e., ratio of current density of forward sweep and that of backward sweep, $\mathrm{I}_{\mathrm{f}} / \mathrm{I}_{\mathrm{b}}$ ).
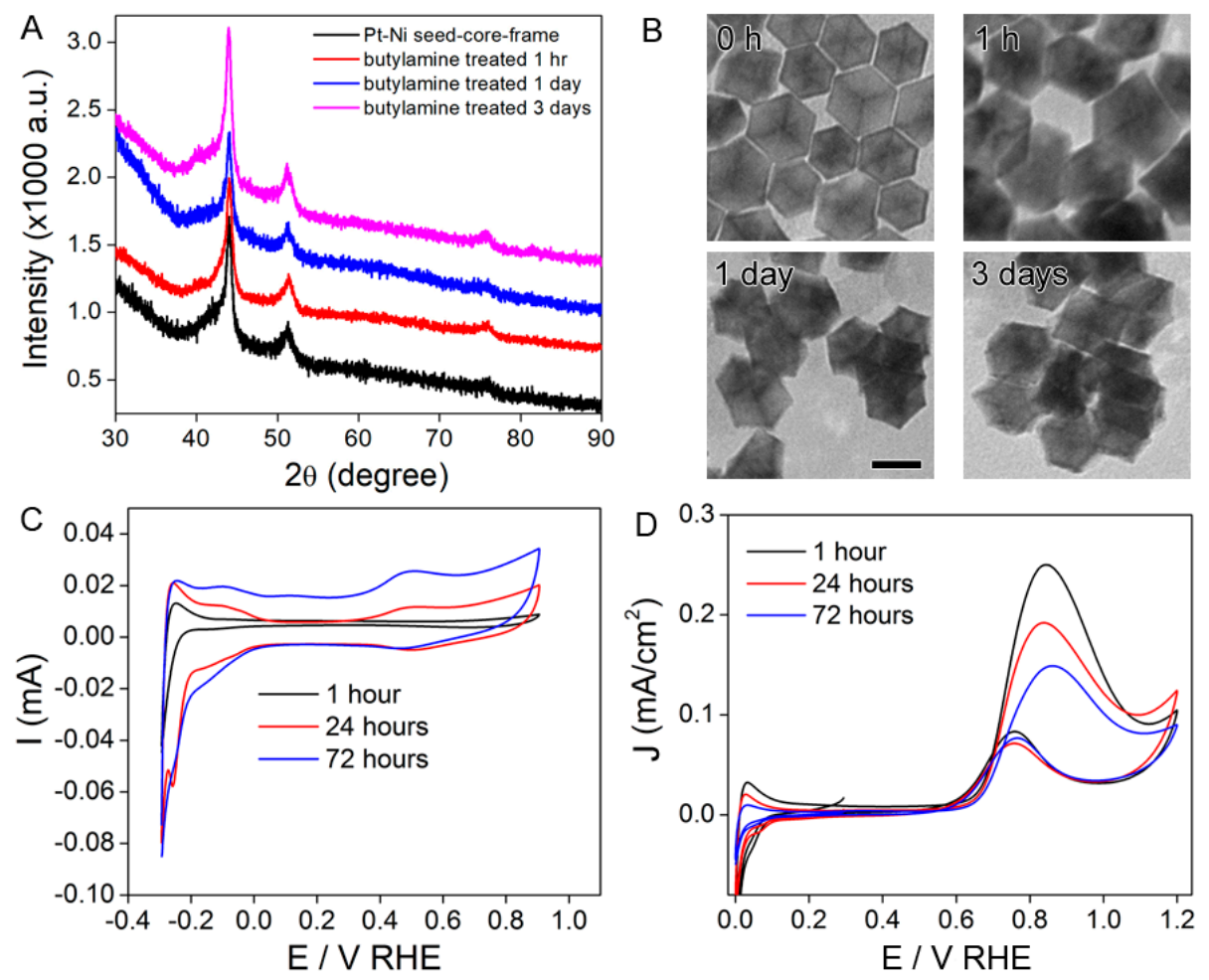

Figure 7. (A,B) Characterization of Pt-Ni seed-core-frame nanostructure with and without butylamine treatment: (A) XRD and (B) TEM images. (C,D) Electrocatalytic measurement of the butylamine treated $\mathrm{Pt}-\mathrm{Ni}$ seed-core-frame nanostructure at a scan rate of $50 \mathrm{mV} / \mathrm{s}$ : (C) cyclic voltammetry (CV) in $0.1 \mathrm{M}$ $\mathrm{HClO}_{4}$ solution and (D) CV in a solution containing $1 \mathrm{M} \mathrm{CH}_{3} \mathrm{OH}$ and $0.1 \mathrm{M} \mathrm{HClO}_{4}$.

Since the $\mathrm{Pt}_{3} \mathrm{Ni}$ alloy nanostructures are more stable under the acidic condition, it is worth evaluating the structural effects on the electrocatalytic properties of the nanocatalysts. As expected, the hollow nanostructures have larger surface area and more active sites for electrocatalysis compared to their solid counterparts. The ECSA of the $\mathrm{Pt}_{3} \mathrm{Ni}$ nanoframes was characterized by $\mathrm{CV}$, compare to that of the $\mathrm{Pt}_{3} \mathrm{Ni}$ nanoparticles (Figure S2) and the commercial carbon supported catalyst $(\mathrm{Pt} / \mathrm{C}$, $20 \mathrm{wt} . \%$ of $\mathrm{Pt}$ ), as shown in Figure 8A. Considering the charge associated with a hydrogen-monolayer desorption on polycrystalline surface is $210 \mu \mathrm{C} / \mathrm{cm}^{2}$ [48], the ECSA were estimated to be 121.2, 80.5, and $85.0 \mathrm{~m}^{2} \mathrm{~g}^{-1}$ for $\mathrm{Pt}_{3} \mathrm{Ni}$ nanoframes, $\mathrm{Pt}_{3} \mathrm{Ni}$ spherical nanoparticles, and $\mathrm{Pt} / \mathrm{C}$, respectively. Without the carbon support, the ECSA of $\mathrm{Pt}_{3} \mathrm{Ni}$ nanoframes was 1.5 times larger than those of $\mathrm{Pt}_{3} \mathrm{Ni}$ and $\mathrm{Pt} / \mathrm{C}$ as a result of their hollow structures. The electrocatalytic activity of the $\mathrm{Pt}_{3} \mathrm{Ni}$ nanoframes for MOR was examined and compared with $\mathrm{Pt}_{3} \mathrm{Ni}$ nanoparticles and $\mathrm{Pt} / \mathrm{C}$ (Figure $8 \mathrm{~B}$ ). The current density of oxidation for the forward sweep $\left(\mathrm{I}_{\mathrm{f}}\right)$ was recorded to be $1.21,0.50$, and $0.54 \mathrm{~mA} / \mathrm{cm}^{2}$ for $\mathrm{Pt}_{3} \mathrm{Ni}$ nanoframes, $\mathrm{Pt}_{3} \mathrm{Ni}$ nanoparticles, and $\mathrm{Pt} / \mathrm{C}$. Compared to $\mathrm{Pt}_{3} \mathrm{Ni}$ nanoparticles and $\mathrm{Pt} / \mathrm{C}$, the $\mathrm{I}_{\mathrm{f}}$ of nanoframes was slightly more than double, suggesting their high efficiency for methanol oxidation. The ratio of $\mathrm{I}_{\mathrm{f}} / \mathrm{I}_{b}$ for $\mathrm{Pt}_{3} \mathrm{Ni}$ nanoframes was 1.29 , comparable with that for the $\mathrm{Pt}_{3} \mathrm{Ni}$ nanoparticles (1.19) and higher than that for Pt/C (0.93). It is implied that alloying Pt with oxiphilic transition metals such as $\mathrm{Ni}$ can oxidize methanol more effectively with less poisoning intermediates adsorbed on the surface compared to the pure $\mathrm{Pt}$ in $\mathrm{Pt} / \mathrm{C}$ [49]. The enhancement of electrocatalytic stability was confirmed by the CA measurements performed at $0.90 \mathrm{~V}$ for $1200 \mathrm{~s}$, as shown in Figure 8C. The decay rate of current density for $\mathrm{Pt}_{3} \mathrm{Ni}$ nanoframes was much slower than those for the $\mathrm{Pt}_{3} \mathrm{Ni}$ spherical nanoparticles and the $\mathrm{Pt} / \mathrm{C}$. The stability of $\mathrm{Pt}_{3} \mathrm{Ni}$ nanoframes was further evaluated by ECSA and 
MOR after the catalyst was continuously sweeping from 0 to $1.2 \mathrm{~V}$ vs. RHE at a scan rate of $50 \mathrm{mV} / \mathrm{s}$ in $0.1 \mathrm{M} \mathrm{HClO}_{4}$ solution. After 250 cycles, the ECSA of the $\mathrm{Pt}_{3} \mathrm{Ni}$ nanoframes remained to be $130 \mathrm{~m}^{2} / \mathrm{g}_{\mathrm{Pt}}$, similar to the initial ECSA (Figure 8D). TEM characterization and atomic absorption analysis revealed that there were few morphological and compositional changes of the nanoframes after the stability test (Figure S3). The electrocatalytic performance of nanoframes remained almost the same values as those obtained after 2 cycles with the $\mathrm{I}_{\mathrm{f}}$ and the $\mathrm{I}_{\mathrm{f}} / \mathrm{I}_{\mathrm{b}}$ ratio recorded to be $1.19 \mathrm{~mA} / \mathrm{cm}^{2}$ and 1.24 , respectively (Figure S4). This result indicated that $\mathrm{Pt}_{3} \mathrm{Ni}$ nanoframes retain their high electrocatalytic properties after 250 cycles of stability test. The high electrocatalytic activity of the $\mathrm{Pt}_{3} \mathrm{Ni}$ nanoframes could be attributed to their unique hollow structure, as well as the bifunctionality of Pt-Ni alloy, which greatly promotes MOR.
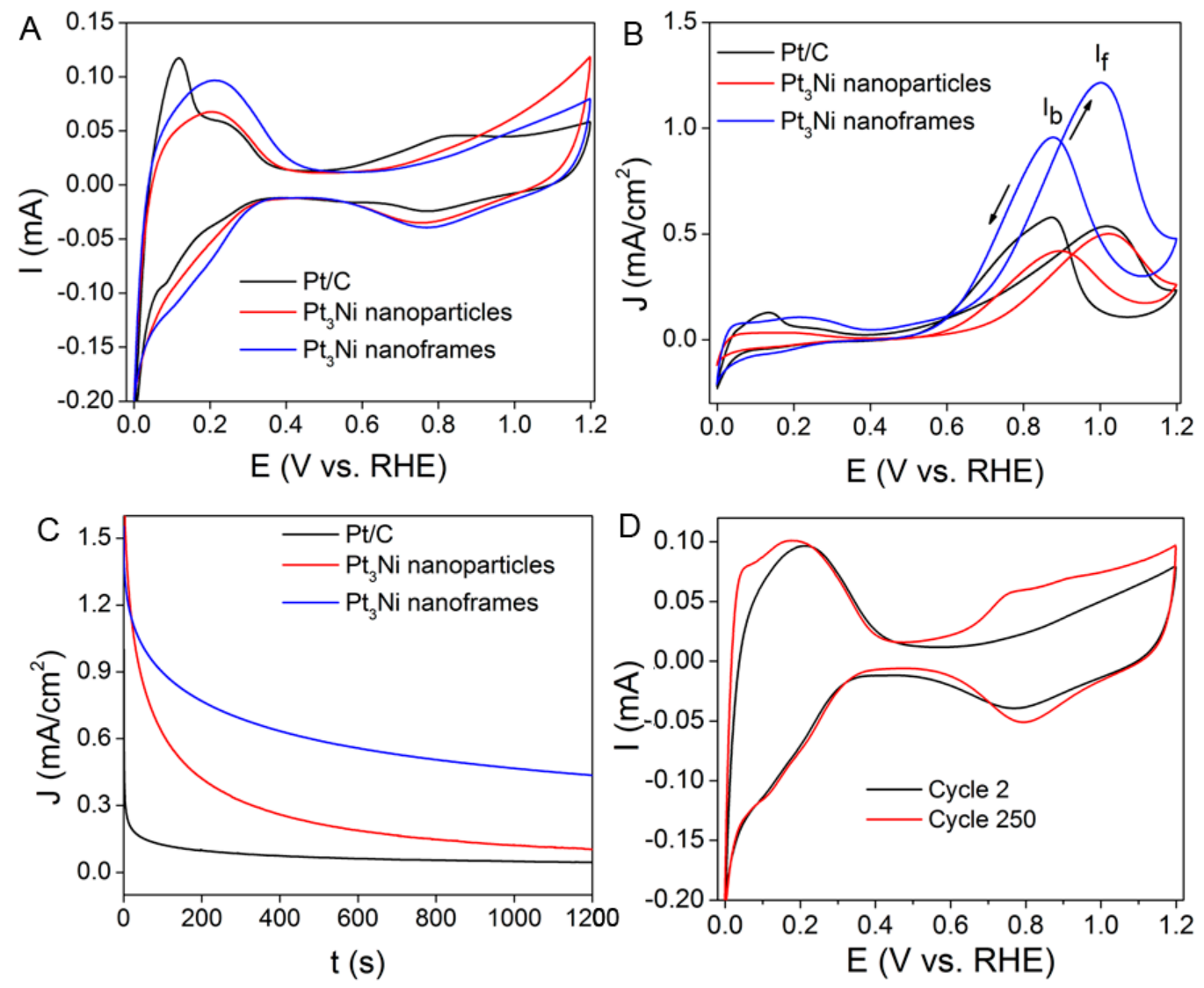

Figure 8. (A) $\mathrm{CV}$ profiles (scan rate: $50 \mathrm{mV} / \mathrm{s}$ ) of $\mathrm{Pt}_{3} \mathrm{Ni}$ nanoframes, $\mathrm{Pt}_{3} \mathrm{Ni}$ nanoparticles, and $\mathrm{Pt} / \mathrm{C}$ catalyst in $0.1 \mathrm{M} \mathrm{HClO}_{4}$ solution. Electrochemical characterization of $\mathrm{CH}_{3} \mathrm{OH}$ oxidation on $\mathrm{Pt}_{3} \mathrm{Ni}$ nanoframes, $\mathrm{Pt}_{3} \mathrm{Ni}$ nanoparticles, and $\mathrm{Pt} / \mathrm{C}$ catalyst in a solution containing $1 \mathrm{M} \mathrm{CH}_{3} \mathrm{OH}$ and $0.1 \mathrm{M}$ $\mathrm{HClO}_{4}$ : (B) CV at a scan rate of $50 \mathrm{mV} / \mathrm{s}$ and (C) Chromoamperometry (CA) obtained at $0.90 \mathrm{~V}$ vs. RHE. (D) CV profiles of $\mathrm{Pt}_{3} \mathrm{Ni}$ nanoframes in $0.1 \mathrm{M} \mathrm{HClO}_{4}$ solution at a scan rate of $50 \mathrm{mV} / \mathrm{s}$.

\section{Materials and Methods}

\subsection{Chemicals}

Nickel (II) 2,4-pentanedionate (Ni(acac) $2,98 \%$ ) and oleylamine (OLA, 90\%) were purchased from Acros Organics, part of Thermo Fisher Scientific, Waltham, MA, USA. Dihydrogen hexachloroplatinate hexahydrate $\left(\mathrm{H}_{2} \mathrm{PtCl}_{6} \cdot 6 \mathrm{H}_{2} \mathrm{O}, 99.9 \%\right.$ ), platinum (II) 2,4-pentanedionate ( $\left.\mathrm{Pt}(\mathrm{acac})_{2}, \mathrm{Pt} 48.0 \%\right)$, potassium tetrachloroplatinate $\left(\mathrm{K}_{2} \mathrm{PtCl}_{4}, 99.9 \%\right)$, butylamine $(99 \%)$, dodecylamine (DDA, $\left.98 \%\right)$, octadecylamine (ODA, 98\%), oleic acid (90\%), and acetic acid $\left(\mathrm{CH}_{3} \mathrm{COOH}\right.$, ACS) were purchased from Alfa Aesar, Haverhill, MA, USA. Hexadecylamine (HDA, 98\%) and polyvinylpyrrolidone (PVP, M.W.=55,000) 
were purchased from Sigma-Aldrich, St. Louis, MO, USA. Tetradecylamine (TDA, 96\%) was purchased from TCI America, Portland, OR, USA. All chemicals were used as received unless specified otherwise.

\subsection{Synthesis of Pt-Ni Seed-Core-Frame Nanostructures}

The Pt-Ni seed-core-frame nanostructures were prepared by a seeded growth method using sequential injection. Briefly, $\mathrm{HDA}(20 \mathrm{mmol}, 5.365 \mathrm{~g})$, and $\mathrm{H}_{2} \mathrm{PtCl}_{6} \cdot 6 \mathrm{H}_{2} \mathrm{O}(0.025 \mathrm{mmol}, 12.95 \mathrm{mg})$ were added to a $25 \mathrm{~mL}$ three-neck flask equipped with a magnetic stir bar. The reaction mixture was heated to $210{ }^{\circ} \mathrm{C}$ under argon. The color of the solution changed from yellow $\left(50-100{ }^{\circ} \mathrm{C}\right)$, to light green yellow $\left(100-180{ }^{\circ} \mathrm{C}\right)$, and gray $\left(210^{\circ} \mathrm{C}\right)$, indicating that the $\mathrm{Pt}(\mathrm{IV})$ was reduced to $\mathrm{Pt}(\mathrm{II})$ and then $\mathrm{Pt}(0)$. Immediately after the reaction the solution turned gray, $\mathrm{Ni}(\mathrm{acac})_{2}(25.2 \mathrm{mg}, 0.1 \mathrm{mmol})$ in $1 \mathrm{~mL}$ of OLA was injected to the reaction. The reaction was allowed to proceed for $20 \mathrm{~min}$ at $210^{\circ} \mathrm{C}$. The product was purified by ethanol and resuspended in ethanol.

\subsection{Synthesis of $\mathrm{Pt}_{3} \mathrm{Ni}$ Nanoframes}

The $\mathrm{Pt}_{3} \mathrm{Ni}$ nanoframes were synthesized by etching the $\mathrm{Pt}-\mathrm{Ni}$ polyhedral nanoparticles with acetic acid. Briefly, $8.0 \mathrm{mg}$ of Pt-Ni seed-core-frame nanostructures, $4.0 \mathrm{~mL}$ of acetic acid $(50 \%), 1.0 \mathrm{~mL}$ of PVP solution $(2.0 \mathrm{mg} / \mathrm{mL})$ were added to an $8.0 \mathrm{~mL}$ vial equipped with a magnetic stir bar. The mixed solution was sonicated for 1 minute, and then immersed into an oil bath set at $60{ }^{\circ} \mathrm{C}$ for different time periods. After the reaction, the product was purified by ethanol and redispersed in water.

\subsection{Instrumentation}

TEM images were captured using a JEOL 1011 microscope (JEOL, Tokyo, Japan) with an accelerating voltage of $100 \mathrm{kV}$. HRTEM images, HAADF-STEM images, and EDS mapping were obtained using a JEOL-ARM 200F microscope (JEOL, Tokyo, Japan) with an acceleration voltage of 200 kV. XRD patterns were acquired using a Rigaku MiniFlex X-ray diffractometer (Rigaku, Tokyo, Japan) equipped with $\mathrm{Cu} \mathrm{K} \alpha$ radiation source operated at $30 \mathrm{kV} / 15 \mathrm{~mA}$. Prior to XRD measurements, the samples were prepared by depositing nanoparticle samples on glass slides. XPS data were collected on an XPS spectrometer from PHI 500 Versa Probe (ULVAC-PHI, Kanagawa, Japan) with Al K $\alpha$ radiation (1486.6 eV). FTIR spectra were obtained using Bruker Tensor 27 (Bruker, Billerica, MA, USA). The concentration of metal contents was determined using a GBC 932 atomic absorption spectrometer (GBC Scientific Equipment, Braeside VIC, Australia).

\subsection{Electrocatalytic Measurement}

$\mathrm{CV}$ and $\mathrm{CA}$ were recorded using a $\mathrm{CHI760} \mathrm{electrochemical} \mathrm{workstation} \mathrm{(} \mathrm{CH}$ Instruments, Austin, TX, USA) at room temperature using a three-electrode cell. The $\mathrm{Ag} / \mathrm{AgCl} / 1.0 \mathrm{M} \mathrm{KCl}$ electrode $\left(E^{o}=-0.294 \mathrm{~V}\right.$ vs. RHE) and Pt wire were used as reference and counter electrode, respectively. Glassy carbon disk $\left(0.070 \mathrm{~cm}^{2}\right)$ was polished to a mirror finish and used as substrate for the working electrode. The catalyst ink was prepared by mixing $1: 1$ volume of $0.8 \mathrm{mg} \mathrm{g}_{\mathrm{Pt}} / \mathrm{mL}$ nanoparticle suspension with $0.05 \mathrm{wt} \%$ Nafion. A $5 \mu \mathrm{L}$ of the ink was pipetted onto the glassy carbon substrate, yielding a Pt loading of $2 \mu \mathrm{g}$ or $28 \mu \mathrm{g} / \mathrm{cm}^{2}$ and dried at room temperature. The electrochemical active surface area (ECSA) was determined from CV profile obtained at a scan rate of $50 \mathrm{mV} / \mathrm{s}$ in $0.1 \mathrm{M} \mathrm{HClO}_{4}$ solution. The methanol oxidation was carried out in a solution containing $1.0 \mathrm{M} \mathrm{CH}_{3} \mathrm{OH}$ and $0.1 \mathrm{M} \mathrm{HClO}_{4}$ at a scan rate of $50 \mathrm{mV} / \mathrm{s}$. The CA was recorded at $0.9 \mathrm{~V}$ vs. $\mathrm{RHE}$ in a solution containing $1.0 \mathrm{M} \mathrm{CH}_{3} \mathrm{OH}$ and $0.1 \mathrm{M} \mathrm{HClO}_{4}$. The electrochemical stability test was carried out at a scan rate of $50 \mathrm{mV} / \mathrm{s}$ with the potential range from 0 to $1.2 \mathrm{~V}$ vs. $\mathrm{RHE}$ in $0.1 \mathrm{M} \mathrm{HClO}_{4}$ solution.

\section{Conclusions}

In summary, we have systematically studied the reaction mechanism of the seeded coreduction method for synthesizing Pt-Ni seed-core-frame nanostructures. The key to the formation of rhombic 
dodecahedra and selective deposition of $\mathrm{Pt}$ on their edges is through the control of the shape of seeds (i.e., the formation of branched seeds using $\mathrm{H}_{2} \mathrm{PtCl}_{6}$ as $\mathrm{Pt}$ precursor) and the ratio of Pt:Ni precursors $\left(\mathrm{H}_{2} \mathrm{PtCl}_{6}: \mathrm{Ni}(\mathrm{acac})_{2}\right.$ in the range of $>1: 1$ to 1:6). The concentration increase of $\mathrm{Ni}(\mathrm{acac})_{2}$ at a fixed amount of $\mathrm{Pt}$ precursor results in the size decrease of the nanostructures due to the additional homogenous nucleation of co-reduced $\mathrm{Pt}$ and Ni. Furthermore, the Ni core of these hierarchical nanostructures could be further etched by acetic acid, leading to the formation of a concave structure and, eventually, hollow nanoframes. By controlling the rates of etching and interdiffusion between the two metals, the morphology and composition of the products could be manipulated. The resultant $\mathrm{Pt}_{3} \mathrm{Ni}$ nanoframes are stable under acidic conditions and possess electronic properties distinctly different from the primary seed-core-frame nanostructures due to the alloying of $\mathrm{Pt}$ with $\mathrm{Ni}$. Owing to the larger surface area and higher density of active sites, the catalytic performance of $\mathrm{Pt}_{3} \mathrm{Ni}$ nanoframes was better than the counterpart $\mathrm{Pt}_{3} \mathrm{Ni}$ nanoparticles and the commercial $\mathrm{Pt} / \mathrm{C}$ catalyst. The mechanism of the seeded co-reduction method can be extended to other Pt-based complex core-frame rhombic dodecahedral nanoparticles. The conversion to their corresponding hollow nanoframes using the low temperature acetic acid etching method may provide a simple means to convert other phase segregated bimetallic polyhedra in order to hollow out alloyed structures with unique morphologies.

Supplementary Materials: The following are available online at http://www.mdpi.com/2073-4344/9/1/39/s1. Figure S1: (A) XPS of the samples collected at 0, 1, and $12 \mathrm{~h}$. (B) Fourier transform infrared (FTIR) spectra of OLA/HDA-capped polyhedral and acetic acid-capped nanoframes. Figure S2: (A) TEM image of $\mathrm{Pt}_{3} \mathrm{Ni}$ nanoparticles with an average diameter of $\sim 6 \mathrm{~nm}$; and (B) XRD patterns of the sample in (A) and its comparison nanoframes as shown in Figure 4. Figure S3: TEM image of $\mathrm{Pt}_{3} \mathrm{Ni}$ nanoframes after 250 cycles. The atomic absorption result indicates a Pt/Ni ratio of 79:21. Figure S4: Electrochemical characterization of methanol oxidation on $\mathrm{Pt}_{3} \mathrm{Ni}$ nanoframes in a solution containing $1 \mathrm{M} \mathrm{CH}_{3} \mathrm{OH}$ and $0.1 \mathrm{M} \mathrm{HClO}_{4}$ at a scan rate of $50 \mathrm{mV} / \mathrm{s}$ : (A) cyclic voltammetry (CV), and (B) chromoamperometry (CA). The CA curves were obtained at $0.90 \mathrm{~V}$ vs. RHE.

Author Contributions: S.C. and J.C. conceived and designed the experiments; S.C. and J.C. performed the experiments and analyzed the data; S.C. and H.W. performed electrochemical measurement; J.T., Y.Z., and H.X. carried out TEM characterization; all authors wrote the paper.

Funding: This research received no external funding.

Acknowledgments: This work was supported in part by the Ralph E. Powe Jr. Faculty Enhancement Award, the startup fund from the University of Arkansas to J.C. We acknowledge partial support from the Center for Advanced Surface Engineering, under the National Science Foundation Grant No. OIA-1457888 and the Arkansas EPSCoR Program, ASSET III. The work done at BNL was supported by the U.S. Department of Energy (Basic Energy Sciences) and by the Materials Science and Engineering Division under Contract No. DE-SC0012704 and through the use of CFN.

Conflicts of Interest: The authors declare no conflict of interest.

\section{References}

1. Rabis, A.; Rodriguez, P.; Schmidt, T.J. Electrocatalysis for Polymer Electrolyte Fuel Cells: Recent Achievements and Future Challenges. ACS Catal. 2012, 2, 864-890. [CrossRef]

2. Wang, D.; Li, Y. Bimetallic Nanocrystals: Liquid-Phase Synthesis and Catalytic Applications. Adv. Mater. 2011, 23, 1044-1060. [CrossRef] [PubMed]

3. Stamenkovic, V.R.; Fowler, B.; Mun, B.S.; Wang, G.; Ross, P.N.; Lucas, C.A.; Marković, N.M. Improved oxygen reduction activity on $\mathrm{Pt}_{3} \mathrm{Ni}$ (111) via increased surface site availability. Science 2007, 315, 493-497. [CrossRef] [PubMed]

4. Wu, J.; Zhang, J.; Peng, Z.; Yang, S.; Wagner, F.T.; Yang, H. Truncated Octahedral $\mathrm{Pt}_{3} \mathrm{Ni}_{\text {Oxygen Reduction }}$ Reaction Electrocatalysts. J. Am. Chem. Soc. 2010, 132, 4984-4985. [CrossRef] [PubMed]

5. $\mathrm{Wu}, \mathrm{J} . ;$ Yang, H. Synthesis and electrocatalytic oxygen reduction properties of truncated octahedral $\mathrm{Pt}_{3} \mathrm{Ni}$ nanoparticles. Nano Res. 2011, 4, 72-82. [CrossRef]

6. Zhang, J.; Yang, H.; Fang, J.; Zou, S. Synthesis and Oxygen Reduction Activity of Shape-Controlled $\mathrm{Pt}_{3} \mathrm{Ni}$ Nanopolyhedra. Nano Lett. 2010, 10, 638-644. [CrossRef]

7. Carpenter, M.K.; Moylan, T.E.; Kukreja, R.S.; Atwan, M.H.; Tessema, M.M. Solvothermal Synthesis of Platinum Alloy Nanoparticles for Oxygen Reduction Electrocatalysis. J. Am. Chem. Soc. 2012, 134, 8535-8542. [CrossRef] 
8. Cui, C.; Gan, L.; Li, H.-H.; Yu, S.-H.; Heggen, M.; Strasser, P. Octahedral PtNi Nanoparticle Catalysts: Exceptional Oxygen Reduction Activity by Tuning the Alloy Particle Surface Composition. Nano Lett. 2012, 12, 5885-5889. [CrossRef]

9. Wang, C.; Chi, M.; Li, D.; Strmcnik, D.; van der Vliet, D.; Wang, G.; Komanicky, V.; Chang, K.-C.; Paulikas, A.P.; Tripkovic, D.; et al. Design and Synthesis of Bimetallic Electrocatalyst with Multilayered Pt-Skin Surfaces. J. Am. Chem. Soc. 2011, 133, 14396-14403. [CrossRef]

10. Wang, C.; Chi, M.; Wang, G.; van der Vliet, D.; Li, D.; More, K.; Wang, H.-H.; Schlueter, J.A.; Markovic, N.M.; Stamenkovic, V.R. Correlation Between Surface Chemistry and Electrocatalytic Properties of Monodisperse $\mathrm{Pt}_{\mathrm{x}} \mathrm{Ni}_{1-\mathrm{x}}$ Nanoparticles. Adv. Funct. Mater. 2011, 21, 147-152. [CrossRef]

11. Chen, C.; Kang, Y.; Huo, Z.; Zhu, Z.; Huang, W.; Xin, H.L.; Snyder, J.D.; Li, D.; Herron, J.A.; Mavrikakis, M. Highly crystalline multimetallic nanoframes with three-dimensional electrocatalytic surfaces. Science 2014, 343, 1339-1343. [CrossRef] [PubMed]

12. Becknell, N.; Kang, Y.; Chen, C.; Resasco, J.; Kornienko, N.; Guo, J.; Markovic, N.M.; Somorjai, G.A.; Stamenkovic, V.R.; Yang, P. Atomic structure of $\mathrm{Pt}_{3} \mathrm{Ni}$ nanoframe electrocatalysts by in situ X-ray absorption spectroscopy. J. Am. Chem. Soc. 2015, 137, 15817-15824. [CrossRef] [PubMed]

13. Niu, Z.; Becknell, N.; Yu, Y.; Kim, D.; Chen, C.; Kornienko, N.; Somorjai, G.A.; Yang, P. Anisotropic phase segregation and migration of $\mathrm{Pt}$ in nanocrystals en route to nanoframe catalysts. Nat. Mater. 2016, 15, 1188-1194. [CrossRef] [PubMed]

14. Becknell, N.; Son, Y.; Kim, D.; Li, D.; Yu, Y.; Niu, Z.; Lei, T.; Sneed, B.T.; More, K.L.; Markovic, N.M. Control of architecture in rhombic dodecahedral Pt-Ni nanoframe electrocatalysts. J. Am. Chem. Soc. 2017, 139, 11678-11681. [CrossRef] [PubMed]

15. Chen, S.; Niu, Z.; Xie, C.; Gao, M.; Lai, M.; Li, M.; Yang, P. Effects of Catalyst Processing on the Activity and Stability of Pt-Ni Nanoframe Electrocatalysts. ACS Nano 2018, 12, 8697-8705. [CrossRef] [PubMed]

16. Ding, J.; Bu, L.; Guo, S.; Zhao, Z.; Zhu, E.; Huang, Y.; Huang, X. Morphology and phase controlled construction of Pt-Ni nanostructures for efficient electrocatalysis. Nano Lett. 2016, 16, 2762-2767. [CrossRef]

17. Gan, L.; Heggen, M.; Cui, C.; Strasser, P. Thermal facet healing of concave octahedral Pt-Ni nanoparticles imaged in situ at the atomic scale: Implications for the rational synthesis of durable high-performance ORR electrocatalysts. ACS Catal. 2015, 6, 692-695. [CrossRef]

18. Beermann, V.; Gocyla, M.; Kuhl, S.; Padgett, E.; Schmies, H.; Goerlin, M.; Erini, N.; Shviro, M.; Heggen, M.; Dunin-Borkowski, R.E. Tuning the Electrocatalytic Oxygen Reduction Reaction Activity and Stability of Shape-Controlled Pt-Ni Nanoparticles by Thermal Annealing-Elucidating the Surface Atomic Structural and Compositional Changes. J. Am. Chem. Soc. 2017, 139, 16536-16547. [CrossRef]

19. Li, Y.; Li, C.; Bastakoti, B.P.; Tang, J.; Jiang, B.; Kim, J.; Shahabuddin, M.; Bando, Y.; Kim, J.H.; Yamauchi, Y. Strategic synthesis of mesoporous Pt-on-Pd bimetallic spheres templated from a polymeric micelle assembly. J. Mater. Chem. A 2016, 4, 9169-9176. [CrossRef]

20. Li, Y.; Liu, Y.; Yamauchi, Y.; Kaneti, Y.; Alsheri, S.; Ahamad, T.; Alhokbany, N.; Kim, J.; Ariga, K.; Wu, N. Micelle-Assisted Strategy for the Direct Synthesis of Large-Sized Mesoporous Platinum Catalysts by Vapor Infiltration of a Reducing Agent. Nanomaterials 2018, 8, 841. [CrossRef]

21. Kani, K.; Zakaria, M.B.; Lin, J.; Alshehri, A.A.; Kim, J.; Bando, Y.; You, J.; Hossain, M.S.A.; Bo, J.; Yamauchi, Y. Synthesis and Characterization of Dendritic Pt Nanoparticles by Using Cationic Surfactant. Bull. Chem. Soc. Jpn. 2018, 91, 1333-1336. [CrossRef]

22. Koenigsmann, C.; Santulli, A.C.; Gong, K.; Vukmirovic, M.B.; Zhou, W.-P.; Sutter, E.; Wong, S.S.; Adzic, R.R. Enhanced Electrocatalytic Performance of Processed, Ultrathin, Supported Pd-Pt Core-Shell Nanowire Catalysts for the Oxygen Reduction Reaction. J. Am. Chem. Soc. 2011, 133, 9783-9795. [CrossRef]

23. Li, H.-H.; Ma, S.-Y.; Fu, Q.-Q.; Liu, X.-J.; Wu, L.; Yu, S.-H. Scalable Bromide-Triggered Synthesis of Pd@Pt Core-Shell Ultrathin Nanowires with Enhanced Electrocatalytic Performance toward Oxygen Reduction Reaction. J. Am. Chem. Soc. 2015, 137, 7862-7868. [CrossRef]

24. Guo, S.; Zhang, S.; Su, D.; Sun, S. Seed-mediated synthesis of core/shell FePtM/FePt (M = Pd, Au) nanowires and their electrocatalysis for oxygen reduction reaction. J. Am. Chem. Soc. 2013, 135, 13879-13884. [CrossRef] [PubMed]

25. Zhang, J.; Mo, Y.; Vukmirovic, M.B.; Klie, R.; Sasaki, K.; Adzic, R.R. Platinum Monolayer Electrocatalysts for O2 Reduction: Pt Monolayer on Pd(111) and on Carbon-Supported Pd Nanoparticles. J. Phys. Chem. B 2004, 108, 10955-10964. [CrossRef] 
26. Adzic, R.R.; Zhang, J.; Sasaki, K.; Vukmirovic, M.B.; Shao, M.; Wang, J.X.; Nilekar, A.U.; Mavrikakis, M.; Valerio, J.A.; Uribe, F. Platinum Monolayer Fuel Cell Electrocatalysts. Top. Catal. 2007, 46, 249-262. [CrossRef]

27. Sasaki, K.; Wang, J.X.; Naohara, H.; Marinkovic, N.; More, K.; Inada, H.; Adzic, R.R. Recent advances in platinum monolayer electrocatalysts for oxygen reduction reaction: Scale-up synthesis, structure and activity of Pt shells on Pd cores. Electrochim. Acta 2010, 55, 2645-2652. [CrossRef]

28. Adzic, R.R. Platinum Monolayer Electrocatalysts: Tunable Activity, Stability, and Self-Healing Properties. Electrocatalysis 2012, 3, 163-169. [CrossRef]

29. Sasaki, K.; Kuttiyiel, K.A.; Wang, J.X.; Vukmirovic, M.B.; Adzic, R.R. Recent Advances in Platinum Monolayer Electrocatalysts for the Oxygen Reduction Reaction. Electrocatal. Low Temp. Fuel Cells Fundam. Recent Trends 2017, 557-584. [CrossRef]

30. Tian, X.L.; Xu, Y.Y.; Zhang, W.; Wu, T.; Xia, B.Y.; Wang, X. Unsupported Platinum-Based Electrocatalysts for Oxygen Reduction Reaction. ACS Energy Lett. 2017, 2, 2035-2043. [CrossRef]

31. Li, C.; Tan, H.; Lin, J.; Luo, X.; Wang, S.; You, J.; Kang, Y.-M.; Bando, Y.; Yamauchi, Y.; Kim, J. Emerging Pt-based electrocatalysts with highly open nanoarchitectures for boosting oxygen reduction reaction. Nano Today 2018, 21, 91-105. [CrossRef]

32. Park, K.-W.; Choi, J.-H.; Kwon, B.-K.; Lee, S.-A.; Sung, Y.-E.; Ha, H.-Y.; Hong, S.-A.; Kim, H.; Wieckowski, A. Chemical and Electronic Effects of $\mathrm{Ni}$ in $\mathrm{Pt} / \mathrm{Ni}$ and $\mathrm{Pt} / \mathrm{Ru} / \mathrm{Ni}$ Alloy Nanoparticles in Methanol Electrooxidation. J. Phys. Chem. B 2002, 106, 1869-1877. [CrossRef]

33. Jiang, Q.; Jiang, L.; Hou, H.; Qi, J.; Wang, S.; Sun, G. Promoting Effect of Ni in PtNi Bimetallic Electrocatalysts for the Methanol Oxidation Reaction in Alkaline Media: Experimental and Density Functional Theory Studies. J. Phys. Chem. C 2010, 114, 19714-19722. [CrossRef]

34. Sulaiman, J.E.; Zhu, S.; Xing, Z.; Chang, Q.; Shao, M. Pt-Ni octahedra as electrocatalysts for the ethanol electro-oxidation reaction. ACS Catal. 2017, 7, 5134-5141. [CrossRef]

35. Wu, Y.; Wang, D.; Zhou, G.; Yu, R.; Chen, C.; Li, Y. Sophisticated construction of Au islands on Pt-Ni: An ideal trimetallic nanoframe catalyst. J. Am. Chem. Soc. 2014, 136, 11594-11597. [CrossRef] [PubMed]

36. Zhou, X.; Gan, Y.; Du, J.; Tian, D.; Zhang, R.; Yang, C.; Dai, Z. A review of hollow Pt-based nanocatalysts applied in proton exchange membrane fuel cells. J. Power Sources 2013, 232, 310-322. [CrossRef]

37. Taylor, E.; Chen, S.; Tao, J.; Wu, L.; Zhu, Y.; Chen, J. Synthesis of Pt-Cu Nanodendrites through Controlled Reduction Kinetics for Enhanced Methanol Electro-Oxidation. ChemSusChem 2013, 6, 1863-1867. [CrossRef] [PubMed]

38. Mathurin, L.E.; Benamara, M.; Tao, J.; Zhu, Y.; Chen, J. Tailoring the Surface Structures of CuPt and CuPtRu 1D Nanostructures by Coupling Coreduction with Galvanic Replacement. Part. Part. Syst. Charact. 2018, 35, 1800053. [CrossRef]

39. Mathurin, L.E.; Tao, J.; Xin, H.; Li, J.; Zhu, Y.; Chen, J. Dendritic Core-Frame and Frame Multimetallic Rhombic Dodecahedra: A Comparison Study of Composition and Structure Effects on Electrocatalysis of Methanol Oxidation. ChemNanoMat 2018, 4, 76-87. [CrossRef]

40. Chen, S.; Jenkins, S.V.; Tao, J.; Zhu, Y.; Chen, J. Anisotropic Seeded Growth of Cu-M (M = Au, Pt, or Pd) Bimetallic Nanorods with Tunable Optical and Catalytic Properties. J. Phys. Chem. C 2013, 117, 8924-8932. [CrossRef]

41. Denton, A.R.; Ashcroft, N.W. Vegard's law. Phys. Rev. A 1991, 43, 3161. [CrossRef] [PubMed]

42. Scherrer, P. Göttinger Nachrichten Math. Phys. Rev. A 1918, 2, 98-100.

43. Holzwarth, U.; Gibson, N. The Scherrer equation versus the'Debye-Scherrer equation. Nat. Nanotech. 2011, 6, 534. [CrossRef] [PubMed]

44. Cui, C.; Gan, L.; Heggen, M.; Rudi, S.; Strasser, P. Compositional segregation in shaped Pt alloy nanoparticles and their structural behaviour during electrocatalysis. Nat. Mater. 2013, 12, 765-771. [CrossRef] [PubMed]

45. Smigelskas, A.; Kirkendall, E. Zinc diffusion in alpha brass. Trans. Aime 1947, 171, 130-142.

46. Yin, Y.; Rioux, R.M.; Erdonmez, C.K.; Hughes, S.; Somorjai, G.A.; Alivisatos, A.P. Formation of hollow nanocrystals through the nanoscale Kirkendall effect. Science 2004, 304, 711-714. [CrossRef] [PubMed]

47. Biegler, T.; Rand, D.; Woods, R. Limiting oxygen coverage on platinized platinum; relevance to determination of real platinum area by hydrogen adsorption. J. Electroanal. Chem. Interfacial Electrochem. 1971, 29, $269-277$. [CrossRef] 
48. Markovic, N.; Grgur, B.; Ross, P. Temperature-dependent hydrogen electrochemistry on platinum low-index single-crystal surfaces in acid solutions. J. Phys. Chem. B 1997, 101, 5405-5413. [CrossRef]

49. Rossmeisl, J.; Ferrin, P.; Tritsaris, G.A.; Nilekar, A.U.; Koh, S.; Bae, S.E.; Brankovic, S.R.; Strasser, P.; Mavrikakis, M. Bifunctional anode catalysts for direct methanol fuel cells. Energy Environ. Sci. 2012, 5, 8335-8342. [CrossRef] 